UDC 821.161.1-31.09 Dostoevskij F. M. https://doi.org/10.18485/ms_zmss.2021.99.4

\author{
Ольга Волчек \\ Санкт-Петербург, независимый исследователь \\ ovoltchek@hotmail.fr
}

Olga Voltchek

St. Petersburg, independent researcher ovoltchek@hotmail.fr

\title{
ДЕНЬГИ В РОМАНЕ Ф. М. ДОСТОЕВСКОГО ИГРОК: ПСИХОАНАЛИЗ, ПАТОЛОГИЯ И ЗДОРОВЬЕ ЛИТЕРАТУРЫ ${ }^{1}$
}

\author{
MONEY IN THE DOSTOYEVSKY'S NOVEL THE GAMBLER: \\ PSYCHOANALYSIS, PATHOLOGY AND HEALTH IN LITERATURE
}

Статья посвящена анализу значения денег в романе Достоевского Игрок в междисциплинарных исследованиях французских ученых, где страсть к азартной игре на рулетке трактуется с точки зрения психоанализа. Впервые тему патологической страсти к игре как мощный импульс к самонаказанию и к саморазрушению обозначил 3. Фрейд в статье «Достоевский и отцеубийство». Получив широкое распространение во Франции с 1973 года, эссе Фрейда послужило отправной точкой для компаративных, литературоведческих, психоаналитических и философских работ, в которых игра на деньги в романе рассматривается не только как моральная перверсия, поведенческая зависимость или иллюзия, навязанная силой желания, но и как возможность свободы и творчества.

Ключевые слова: Достоевский, Фрейд, деньги, игра, патология, психоанализ.

The article attempts to analyse the role of money in Fiodor Dostoyevsky's novel The Gambler as seen through French interdisciplinary scientific studies that interpret roulette gambling from the psychoanalytical standpoint. In his article "Dostoyevsky and Patricide" Freud was the first to consider pathological addiction to games as a poweful impulse for self-punishment and self-destruction. Largely diffused in France since 1973, Freud's essay served as a starting point for comparative, literary, psychoanalytical and philosophical papers that see gambling in the novel not only as moral perversion, behavioural addiction and illusion, but also as possibility of freedom and art.

Key words: Dostoyevsky, Freud, money, gambling, pathology, psychoanalysis.

«Француз тих, честен, вежлив, но фальшив, и деньги у него все», писал Достоевский Страхову из Парижа в 1862 году. Это было первое

1 Исследование выполнено при финансовой поддержке РФФИ в рамках научного проекта № 18-012-9001: «Междисциплинарная рецепция творчества Ф. М. Достоевского во Франции 1968-2018 годов: филология, философия, психоанализ». 
заграничное путешествие русского писателя, первое знакомство со «страной святых чудес» и первый опыт игры на рулетке в курзале Висбадена. Наиболее ярко меркантилизм Запада и французов, в частности, показан в «Зимних заметках о летних впечатлениях» (1863) и в романе Игрок (1866), где главный герой, заражаясь идеей легкого обогащения, превращается в патологического игрока. Французские исследователи (С. Олливье, Ж. Катто, К. Аддад) неоднократно обращались к рассмотрению темы денег в жизни и творчестве Достоевского, накопив довольно много ценных наблюдений. Но в этой работе тема денег нас будет интересовать в контексте анализа патологической страсти к игре на рулетке на материале романа Игрок. При этом мы сосредоточим наше внимание не столько на классических литературоведческих работах, сколько на междисциплинарных исследованиях, где страсть к рулетке, изначально вызванная острой необходимостью в деньгах и жаждой выигрыша как способу легкого и быстрого обогащения, трактуется с точки зрения психоанализа, и переносится в новейшие психоаналитические, компаративные или философские исследования романа Достоевского.

Впервые тему игры у Достоевского в перспективе психоанализа обозначил 3. Фрейд (1856-1939) в известной работе «Достоевский и отцеубийство» (1928), послужившей предисловием к изданию «первообраза» Братьев Карамазовых в немецком переводе 2 . Во Франции этот текст Фрейда появился также в качестве предисловия, правда, к французскому переводу воспоминаний А. Г. Достоевской, выпущенным в свет издательством «Галлимар» в 1930 году33. Не получив широкой огласки в 30 60 -е годы XX века, это эссе Фрейда все же исподволь повлияло на первые критические работы о Достоевском, принадлежавшие главным образом французским критикам и писателям. Но широкую известность статья Фрейда получила после публикации в 1973 году в переводе известного французского философа и психоаналитика Ж.-Б. Понталиса (1924-2013), опять же в виде предисловия к роману Братья Карамазовы в массовом издании карманного формата. Такое издательское решение, безусловно, было коммерческой уловкой, несмотря на весьма редукционистскую трактовку произведения и самой личности писателя, предложенную отцом-основателем психоанализа. Тем не менее, этот в общем-то довольно проходной для Фрейда текст, написанный по случаю, нехотя, по просьбе самого преданного ученика М. Эйтингона (1881-1943), оказал

2 Речь идет об издании рукописей Достоевского в книге «Ф. М. Достоевский. Первообраз "Братьев Карамазовых": источники, планы и фрагменты Достоевского» с обширным комментарием В. Л. Комаровича, изданной в 8-томной издательской серии «Наследие Достоевского» (1925-1931) немецким издательством «Пипер» (“Piper-Verlag”). См. об этом: (Богданова 2017)

3 Эта полузабытая книга была переиздана в 2001 году с предисловием Ж. Катто. См.: Dostoïevski: mémoires d'une vie/Anna Grigorievna Dostoïevskaïa. Trad. du russe par André Beucler, préf. de Jacques Catteau. Paris: Mémoire du livre (2001). 
и продолжает оказывать ощутимое влияние на интерпретации творчества Достоевского во Франции.

Столь устойчивый интерес к этому эссе Фрейда во Франции требует небольшого предварительного историко-литературного комментария. Необходимо подчеркнуть, что в истории психоаналитических прочтений и толкований творчества Достоевского французская традиция занимает особое место. В отличии от России, где психоаналитические исследования литературы, получив мощный импульс в 20-е годы XX века, лишь в последнее время возвращаются в активное пространство литературоведения, во Франции «психоанализ и литература с самого начала находятся в привилегированных отношениях и до сих пор поддерживают органическую связь» (Catteau 2004: 157). Определенного рода разрыв в традиции психоанализа личности и творчества Достоевского имел место и в немецкой культуре, также подчинившейся диктату идеологии, по меньшей мере, в лице тех исследователей и писателей, которые не приняли эмиграции. Таким образом, именно во Франции психоаналитический метод в приложении к литературе, в том числе, в отношении Достоевского, развивался скорее органично, что нашло отражение не только в работах литературоведов и философов, но также в психиатрии и психоанализе.

Во Франции психоанализ прививался медленно, преодолевая мощное сопротивление как в медицинских кругах, так и в общекультурной сфере, что объяснялось также отсутствием переводов работ Фрейда на первом этапе рецепции. Большинство французских врачей-психиатров относились к венской интеллектуальной моде более чем сдержанно, что было обусловлено также влиянием национальной научной школы невропатологии Ж. М. Шарко (1825-1893), у которого, как известно, Фрейд проходил стажировку. Таким образом отношения Фрейда с Францией определенное время оставались под знаком враждебности и непонимания (Sédat: 2011). Для нашей темы необыкновенно существенным оказывается то обстоятельство, что появление первых переводов из Фрейда на французский язык, благодаря которым психоанализ вошел в моду, совпало со второй волной интереса к творчеству Достоевского, которая буквально захлестнула литературную Францию в начале 20-х годов в связи с празднованием столетия русского писателя (Фокин: 2013). Юбилею была посвящена характерная подборка в журнале Nouvelle revue française (№ 101, 1922), где во французском переводе вышли «Два письма» Достоевского, а также статьи А. Жида «Достоевский», Ж. Ривьера «О Достоевском и непостижимом» и перевод работы Л. Шестова «Достоевский и преодоление самоочевидностей». При этом предыдущий номер журнала (№ 100), который позиционировал себя именно как рупор новой литературной Франции, чуждой как крайностям художественного авангарда, так и обыкновенному консерватизму католической литературной традиции, открывался статьей знаменитого писателя-унани- 
миста Ж. Ромена (1885-1972) «Обзор психоанализа»: с нее начинается триумфальное шествие учение Фрейда во французской культуре, знамя которого вскоре будет подхвачено сюрреалистами (Roudinesco: 1982). Таким образом, Достоевский и Фрейд оказались в одной культурной «связке»: французский перевод Введения в психоанализ, выполненный еврейско-российским переводчиком С. Янкелевичем (1869-1951) и авторизованный автором, вышел в свет в том же юбилейном 1921 году.

Первые опыты толкования личности и творчества Достоевского в духе Фрейда были нацелены главным образом на то, чтобы найти доказательства и продемонстрировать неоспоримую ценность психоанализа. Таким образом, литература играла на руку психоанализу. В этом отношении показательна вышедшая в 1923 году на немецком языке работа ученицы Фрейда Иолан Нейфельд «Достоевский. Психоаналитический очерк» (Нейфельд 1925), где жизнь и творчество русского писателя объясняются Эдиповым комплексом, который Достоевский якобы никогда не мог преодолеть. Приступы азарта, в том числе в игре на рулетке, автор также сводила к этому комплексу, утверждая, что «причиной была не только жажда денег, но и бессознательная детерминация» (Нейфельд 1925: 66), отсюда же следовал вывод о бессознательном значении денег у Достоевского, которые приобретали очертания фигуры Отца. Фрейд высоко оценил этот опус Нейфельд, что, по мнению некоторых исследователей, могло послужить причиной его сдержанного отношения к самой задаче написания предисловия к Братьям Карамазовым. С другой стороны, как отмечает М.-Т. Нейро-Сутерман ${ }^{4}$ в статье, посвященной анализу этого эссе (Neyraut-Soutterman 1970), Фрейду понадобилось два года — с 1926 по 1928, чтобы завершить довольно небольшой текст, что также было для него не свойственно и требовало какого-то объяснения. Вместе с тем, существует мнение, что Фрейду было трудно работать над истолкованием опыта писателя, в котором преобладало «мистическое» начало, работая одновременно над книгой Будущее одной иллюзии (1927), где он разоблачал власть и иллюзию религии. Но по мысли Нейро-Сутерман эти два текста Фрейда скорее опираются друг на друга, а трудности заключаются в другом: они заложены в самой литературе. В эссе «Достоевский и отцеубийство» Фрейд замечает: «К сожалению, перед проблемой поэтического творчества психоанализ должен сложить оружие» (Фрейд 1995: 285). Позже в предисловии к книге М. Бонапарт об Э. По (1933) он уточняет, что «такие исследования не обязаны объяснять гений художника, но они показывают, какие мотивы его пробудили и какой материал (сюжеты) ему принесла судьба» (Фрейд 1995: 252). Нейро-Сутерман высказывает предположение, что Фрейд питал некую скрытую зависть по отношению к писателю, оставаясь перед ним «кро-

4 Мари-Терез Нейро-Сутерман - психоаналитик, автор компаративного исследования об эпилепсии Достоевского и Флобера (1993). 
потливым ремесленником, вынужденным мучительно реконструировать с помощью анализа то, чего тот непосредственно добивается в произведении в качестве продукта познания психической природы человека и труда художника» (Нейро-Сутерман 1970: 652).

В письме к Т. Райку, написавшему критический отзыв о статье Фрейде, где упрекал мэтра в том, что тот не уделил внимания Достоевскому как «великому психологу», Фрейд писал, что он полностью подчиняет Достоевского-психолога Достоевскому-творцу и видит в нем лишь «патологическую натуру», к которой он как врач не испытывает симпатии: «Достоевского я просто не люблю. Это связано с тем, что я расходую все свою терпимость по отношению к патологическим натурам во время анализа. В искусстве и жизни я их не переношу» (Цит. по: Энциклопедия глубинной психологии 1998: 80-81). При этом Фрейд остается моралистом: его чувства на стороне того, кто не поддается искушению, кто может сопротивляться влечениям, а не кающийся грешник. Здесь важно отметить определенную параллель между двумя текстами Фрейда в том, что касается русской натуры, русской души. В Будущзем одной иллюзии Фрейд пишет: «Русская душа отважилась сделать вывод, что грех - необходимая ступенька к наслаждению всем блаженством божественной милости, то есть в принципе богоугодное дело» (Фрейд 1989: 125). В эссе о Достоевском он утверждает, что русский писатель уязвим скорее всего как моралист: «Признавая его высоконравственным человеком на том основании, что высшей ступени нравственности достигает только тот, кто прошел через бездны греховности, мы упускаем из виду одно соображение. Ведь нравствен тот, кто реагирует уже на внутренне воспринимаемое искушение, не поддаваясь ему» (Фрейд 1995: 285) и полагает далее, что сделка с совестью скорее всего типично русская черта. Вместе с тем, Фрейд, наследуя позитивистскому детерминизму XIX века, остается чужд поиску свободы, на который делает ставку русский писатель. В этой медикалистской перспективе свободная воля - не более чем иллюзия, которой поддался Достоевский. Отсюда и упрек в том, что тот, предаваясь исканию свободы, в конечном итоге подчиняется Богу и Государю и, то есть государственному и религиозному авторитету, двум инстанциями, с которыми устанавливается отношение, равноценное отношению «сын-отец».

Следует отметить, что «Достоевский и отцеубийство» - самый знаменитый психоаналитический текст об игре, при том, что роман Игрок в нем даже не упоминается. Фрейд подходит к вопросу о симптоме игрока с точки зрения Эдипова комплекса. Он опрокидывает перспективу, сделав игру, по крайней мере, в отношении Достоевского, необходимостью наказания отца через судьбу, которая, по мнению Фрейда, в конце концов «всего лишь более поздняя проекция отца» (Фрейд 1995: 289). С другой стороны, патологическая страсть к игре напрямую связа- 
на с творческим процессом, который запускается лишь тогда, когда все проиграно, когда деньги обретают нулевую степень капитализации.

Во Франции особое преломление тема патологической игры на деньги получила развитие в прикладном психоанализе, который по справедливому замечанию известного психоаналитика А. Грина, высказанному в предисловии к сборнику статей Психоанализ и литература, заключается в «психоаналитических интерпретациях произведений искусства и литературы, которые, обладая своей спецификой, вовсе не претендуют на исчерпывающий характер или последнее слово в литературной критике» (Green 2002: VIII). Вместе с тем, подчеркивая, что литературу и психоанализ во Франции связывает давняя традиция, необходимо не упускать из виду, что работы Фрейда по литературе, включая знаменитое эссе о «Беспокойной странности» («Жуткое», «Зловещее» 1919), а также этюд о Братьях Карамазовых, образуют своего рода фундамент психоаналитического литературоведения.

Психоаналитическое прочтение романа Игрок предлагает Д. Фернандес ${ }^{5}$, автор книги Древо до самых корней. Психоанализ и творчество (1972) и изобретатель термина и метода психобиографии. Исходя из дорогого Сент-Бёву постулата («каково дерево, таковы и плоды»), согласно которому понять произведение возможно не иначе как пролив свет на личность автора, психобиограф исследует раннее детство человека и его первичное семейное окружение, чтобы обнаружить «бессознательную личность» (Fernandez 1970: 33-48). В 1973 г. Фернандес пишет предисловие к роману Игрок, выпущенному издательством «Галлимар» в той же серии, что и Братья Карамазовы. Не отходя от постулатов Фрейда, нашедшего объяснение и смысл этой пагубной страсти к игре в новелле С. Цвейга «Двадцать четыре часа из жизни женщины», Фернандес, рассматривая садомазохистскую любовь главного героя к Полине, обращает внимание читателя на столь характерный для Достоевского иррациональный, абсурдный характер любви, когда страсть находит утоление в убийстве, что позволяет автору предисловия прийти к заключению, что Игрок является «бесценным свидетельством "философии" великого писателя», а также «резервуаром и суммой всех идей Достоевского» (Fernandez 1973: 15).

Появление двух психоаналитических прочтений романов Достоевского в массовой серии такого авторитетного издательства как «Галлимар» способствовало укреплению связи между двумя первооткрывателями сферы бессознательного, каковыми в восприятии французов стали Достоевский и Фрейд. Таким образом, наряду со статьей Фрейда роман Игрок по сей день остается важным источником для анализа различных видов патологической зависимости. Практикующие психоаналитики, психологи и психиатры часто обращаются в своих теоретических рабо-

5 Доминик Фернандес — писатель, профессор, член Французской академии. 
тах к литературным произведениям, в частности к роману Достоевского для изучения проблематики игры у своих пациентов.

Так А. Эйгер 6 в статье «Достоевский, убийца или игрок» (Eiguer 2002), отталкиваясь от эссе Фрейда и квалифицируя его как слишком личное по отношению к русскому писателю, сосредотачивает внимание на теме перверсии, оговариваясь при этом, что личность и творчество Достоевского трудно рассматривать только в этом направлении. Тема патологической игры вызывает реакции разного рода, но с клинической точки зрения ее можно рассматривать как моральную перверсию, ставя в один ряд с такими «нарциссически-перверсивными фигурами, как моральные мазохисты, клептоманы, пироманы, самозванцы, мошенники и интриганы» (Eiguer 2002: 25).

Анализируя статью Фрейда, Эйгер подчеркивает, что Фрейд выделяет три черты характера Достоевского: чрезвычайно высокую возбудимость, задатки извращенных влечений и собственно художественное дарование, в сущности, в этом проявляется «весь интерес Фрейда к экономической и количественной проблеме» (Eiguer 2002: 28). Говоря об игре в жизни Достоевского, Эйгер высказывает предположение, что она является чем-то вроде прививки, благодаря которой писатель на время получает доступ к «нормальному» существованию. Если рассматривать игру на рулетке как моральную перверсию, то ее источником будет неистовство автора, лудопатия, которой он инфицирует своих персонажей. О страсти к игре говорит и сам Достоевский. Но это не только страсть, утверждает Эйгер, — это «постоянное напряжение, лихорадочное ощущение (чего-то, что его пронизывает, и, следовательно, управляет им изнутри), своего рода ощущение единственного наслаждения, которого он не находит в других ситуациях» (Eiguer 2002: 34).

Характеристики такого рода личности восходят к роману Игрок. В романе есть три оси, точнее, три переплетенных нити: игра с ее живописным миром, сентиментальная проблематика и взгляд на русских, проживающих заграницей. Эйгер пытается проникнуть в логику русского игрока. В отличие от немцев, играющих «с головой», русские играют «зря и без труда», как рассуждает герой романа, для них игра - своего рода дебош, повиновение принципу траты, прожигания жизни. В игре русские словно забывают себя, забывая окружающий мир, подчиняясь логике автоэротизма: «автоэротизм в его самом разрушительном измерении требует смерти объекта» (Eiguer 2002: 40). Для игрока денежный выигрыш - это всего лишь предлог, повод для новой ставки. Ссылаясь на американского психолога Э. Берглера и его известную работу Психология игрока7, Эйгер утверждает, что под влиянием мазохизма, игрок

6 Альберто Эйгер, психиатр-психоаналитик, специалист по моральной перверсии, профессор университета Пари-Декарт.

7 Bergler E. The psychology of gambling. New York International University, 1957. 
скорее бессознательно стремится к проигрышу. В терминах философии экономики эту ситуацию можно выразить как порыв к обнулению капитала, как поиск того ничто, исходя из которого можно запустить новый цикл производства литературы.

Вместе с тем, игра для героя романа — это воспроизводство любовного опьянения, он пытается постичь тайну иллюзии, средоточие влечения, природу страсти. Он ищет не богатства, а нищеты, не капитала, а утраты себя, вплоть до собственного достоинства. Он движим волей к страданию, без которого он не чувствует, что существует. Я страдаю, следовательно существую, мог бы сказать Достоевский. Оторванность персонажа от России, отсутствие почвы для достоверного «Я» выливается в своеобразную нехватку как динамическую негативность, внутреннюю пустоту, открытую для сильных влечений, впечатлений, наваждений. Пустота, или отсутствие, «Я» оборачивается триумфом своеволия, вариантом садомазохизма, формы которого принимает любовь к Полине, которую ему хочется «съесть». Речь идет не об убийстве отца, а об убийстве любимой женщины. Здесь Эйгер высказывает предположение, что речь идет скорее об убийстве самой любви: перверсивные персонажи никогда не убивают, им важно сохранить объект для погони за наслаждением.

В сходном ключе разворачивается статья «Патологическая игра: литературные и культурные аспекты», опубликованная М. Лежуайе 8 в специальном психоаналитическом журнале: здесь игра на деньги определяется как «поведение, отклоняющееся от своей функции игры или свободы» (Lejoyeux 2006: 232). Патологический игрок отдаляется от «нормальной» игры как источника развлечения и удовольствия, утрачивая свободу выбора играть или не играть. При этом пагубные последствия такой игры не сводятся к финансовым потерям и долгам: ее можно отнести к категории психических отклонений, «поведенческой зависимости» (Lejoyeux 2006: 233). Рассматривая игрока как романного персонажа в литературе и психоанализе, автор выделяет Достоевского как самого знаменитого писателя-игрока, создавшего галерею персонажей, играющих на рулетке против казино или против судьбы, которая им противостоит. По мысли автора, портрет игрока, созданный Достоевским, является и «прекрасным примером русского романа, и все еще актуальным психологическим анализом, и формой автопортрета» (Lejoyeux 2006: 239). Страсть к игре, вызванная острой необходимостью в деньгах, трактуется, в духе Фрейда, как мощный импульс к самонаказанию и саморазрушению. Таким образом, желание игры проявляется как желание проигрыша в сугубо мазохистском ключе, осложненном фантазмом отцеубийства. У писателей, так же как у психоаналитиков

8 Мишель Лежуайе - психиатр, специалист по аддиктологии, профессор университета Дени Дидро. 
«невроз игры» — это конфликт между Я и неумолимой судьбой, субститутом отца. Игрок выступает против всемогущего, далекого и неосязаемого противника - случая, за фигурой которого маячит фигура Отца. Игрок взывает к случаю, чтобы получить ответ на вопрос о всемогуществе. Вместе с тем, следует признать, что несмотря на многочисленные исследования и клинические наблюдения, загадка патологического характера игры, которая одновременно является страстью, наркотиком и желанием испытать судьбу, остается неразгаданной. Такое поведение, которое исходит как из стремления к богатству и благосклонности судьбы, так и из игры, направленной на разорение, на разрушение себя продолжает завораживать исследователей, философов и художников.

Среди французских работ, посвященных теме игры у Достоевского, необходимо остановиться на тексте А. Конт-Спонвиля. Известный французский философ, убежденный материалист и атеист, называвший Фрейда в числе своих учителей, также обращается к роману Достоевского и пишет предисловие к новому переводу Игрока, который был опубликован в издательстве «Actes Sus»: речь идет об эссе, написанном в жанре авторского прочтения (lecture) и озаглавленном в память о знаменитом романе Л.-Ф. Селина Из страсти к страсти (Comte-Sponville: 1991).

Игрок - это роман о страсти или роман о страстях - к женщине и к игре, которые сливаются воедино и составляют одно целое, одну страсть. По мысли французского философа, истинная страсть всегда исключительно эгоцентрична. Страстно любят только себя или для себя, объект не имеет или теряет значения. Урок Достоевского заключается в том, что он показывает монструозность страсти: любая страсть чудовищна. Но еще более чудовищным был бы отказ от страсти. Мы любим лишь саму любовь, ибо не умеем любить. Вот почему наша жизнь обречена на провал: в ней нет места другому. Достоевский - игрок, он желает обогатиться, но делает все, чтобы разориться. Поскольку игра на рулетке - это искусственно созданная ситуация, именно она обнажает искусственную природу любой страсти. И дело не в том, что люди не любят деньги. «Деньги - все!», говорит Алексей Иванович. То есть, они являются универсальным эквивалентом согласно Марксу, в том числе и для тех, кто не любит деньги ради них самих. Но персонаж Достоевского не любит деньги, они нужны ему, чтобы послужить любви. Этот парадокс французский философ также объясняет с опорой на Фрейда: статья «Достоевский и отцеубийство» является своего рода неисчерпаемым катализатором мысли о природе страсти к игре. Игра дает формулу страсти, иллюзии, надежды, и это одна и та же формула. Есть только желание. Есть только воображение. Объект не имеет значения. Эта женщина или другая, рулетка или политика, деньги или любовь. Достоевский дает нам понять то, что шестьдесят лет спустя будет пытаться объяснить Фрейд: вера, истинная или ложная, есть не что иное, как иллюзия, навязанная силой нашего желания. Равно как страсть. Подобно 
тому, как юная пастушка может жить иллюзией, что придет прекрасный принц и увезет ее с собой, как замечает в Будущем одной иллюзии Фрейд, игрок, убежденный в силу своей страсти в том, что он выиграет, строит иллюзии, и при этом не важно выиграет он или нет. Очевидно, что вера была основана не на знании, не на расчете, она строится на мощном желании. Иллюзия - это желание, принимающее себя за истину, надежда, принимающая себя за доказательство. Достоевский сам бросает играть, и единственным спасением от отчаяния для него останется Бог, поскольку формула иллюзии (верить в то, чего желаешь) это также формула веры. По мысли французского философа, религия - это всего лишь игра на квит, метафизический расчёт в игре. В этой перспективе Достоевский просто сменил одну рулетку на другую, перешел от одной страсти к другой.

Наряду с философским рассмотрением игры как страсти, тема игры на рулетке трактуется в терминах освобождения в компаративном исследовании Ж. Вьон-Дюри, посвященном теме игры у Достоевского (Игрок) и С. Цвейга («Шахматная новелла») (Vion-Dury 2016). Исследовательница ставит акцент на параллели романа Игрок с Записками из мертвого дома, утверждая, что с пространственной точки зрения Игрок организован как сошествие в царство мертвых, в другую каторгу, в своего рода ад, который по выражению самого Достоевского 9 представляет игра на рулетке (Vion-Dury 2016: 117). Игра в романе ассоциируется с проигрышем, «с потерей, с потерянной страной, и ее фундаментальными ценностями» (Vion-Dury 2016: 122). Вместе с тем роман говорит о своего рода поправках, о желании внести поправки в закон и в договор. На самом деле, рожденный в результате договора, роман рассказывает истории о договорах, по большей части невыполненных. Но все эти неравноправные, оскорбительные, мазохистские договоры все же представляют собой положительный противовес тому единственному (и, по мнению Достоевского, несправедливому) договору поколений в этике немецкого накопления, которое Достоевский отвергает и осуждает. Так рулетка забирает или раздает то, что с трудом копил годами условный «отец немецкого семейства». Таким образом, игра обеспечивает свободу, позволяет быть щедрым и центробежным русским игроком, тогда как экономия питает центростремительный немецкий материализм. Игра, таким образом, служит Богу, нации и морали.

Исследовательница также отмечает, что Фрейд посвящает немалую часть своего эссе анализу новеллы Цвейга «Двадцать четыре часа из жизни женщины», исходя из которого он интерпретирует личность Достоевского-игрока. Психоаналитик связывает практику игры с практикой «игры рук», а также с фантазмом о сексуальной инициации сына

9 См. письмо Н. Н. Страхову из Рима от 18 сентября 1863 г., где впервые появляется замысел романа. 
матерью. Но она отмечает сугубо позитивную роль женщин старшего возраста на игрока (бабушка и незнакомая женщина в казино, которые уговаривают его бросить игру и уйти) и связывает образ женщины с ушедшей матерью, матерью-землей и прежней жизнью, потерянной в Игроке и в «Шахматной новелле». Задаваясь вопросом, может ли женщина-мать выиграть партию против патологической страсти игроков, исследовательница полагает, что это возможно при условии, что отношения с матерью вернутся в игру, в смысле того живого обмена, который английский психиатр Д. В. Винникотт (1896-1971) описывает в книге Игра и реальность (1971). Таким образом, игра заключает в себе возможность свободы и творчества.

В этой работе мы рассмотрели ряд новейших трактовок темы игры как патологии, представленных в различных дисциплинах современных гуманитарных наук Франции: литературоведении, психоанализе, философии. Все они так или иначе опираются на основополагающую работу 3. Фрейда «Достоевский и отцеубийство», несмотря на редукционистский характер этого опуса, написанного отцом-основателем психоанализа под знаком амбивалентного отношения «учитель-ученики», в котором несложно увидеть вариант отношения «отец-дети». В задачи этой работы не входит последовательная критика психоаналитической трактовки темы игры, тем не менее заметим, в завершение этого критического обзора, что психоанализ, сосредотачиваясь на «психее», не видит за одним древом целого леса, то есть множества отношений и связей, обуславливающих как внутреннюю личность писателя, так и те истории, в которых он проецирует себя вовне, в том числе, силой литературы. Фрейд и его последователи так или иначе устремлены к «нормализации» человеческого существования, которую утверждают за счет патологизации литературного опыта; но писатель - не больной, даже когда страдает от той или иной зависимости; писатель - скорее диагност; заключение, которое он выносит человеку, основывается на опыте здоровья, которого все время ищет автор через литературу.

\section{ЛИТЕРАТУРА}

Богданова Ольга. «Миф Достоевского в России и Германии 1920-х годов: перипетии и парадоксы культурного трансфера». Mundo Eslavo 16 (2017): 9-18.

Нейфельд Иолан. Достоевский. Психоаналитический очерк. Под ред. Проф. 3. Фрейда. Пер. с немецкого Я. Друскина. Ленинград — Москва: Издательство «Петроград», 1925.

Фокин Сергей. Фигуры Достоевского во франиузской литературе ХХ века. Санкт-Петербург: РХГА, 2013.

Фрейд Зигмунд. «Будущее одной иллюзии». Сумерки богов. Ф. Ницше, З. Фрейд, Э. Фромм, А. Камю, Ж. П. Сартр. Москва: Политиздат, 1989: 94-142.

Фрейд Зигмунд. Художник и фантазирование. Пер. с нем. Под ред. Р. Ф. Додельцева, К. М. Долгова. Москва: Издательство «Республика», 1995. 
Эничиклопедия глубинной психологии. Том 1. Зигмунд Фрейд. Жизнь, работа, наследие. Москва: MGM-Interna, 1998: 80-81.

Comte-Sponville André. «D’une passion l'autre». Dostoïevski Fédor. Le joueur: extraits des carnets d'un jeune homme, nouvelle traduction d'André Markowicz, lecture d'André Comte-Sponville. Arles: Actes Sud, 1991: 219-234.

Eiguer Alberto. «Dostö̈evski, meurtrier ou joueur». Babel: psychanalyse et littérature: [actes du séminaire]. Dir. M. Corcos, P. Lévy-Soussan, E. Sabouret, M. de M’Uzan, F. Richard, M. Coppel-Batsch... [et al.]. Paris: EDK, 2002: 25-54.

Fernandez Dominique. «Introduction à la psychobiographie». Nouvelle Revue de psychanalyse. 1 (1970): 33-48.

Fernandez Dominique. «Préface». Dostoïevski. F. Le Joueur. Paris: Gallimard, 1973: 1-15.

Freud Sigmund. «Dostoïevski et le parricide». Dostoïevski A. G. Dostoïevski par sa femme. Paris: Gallimard, 1930: 15-33.

Green André. «Préface». Babel: psychanalyse et littérature: [actes du séminaire]. Dir. M. Corcos, P. Lévy-Soussan, E. Sabouret, M. de M’Uzan, F. Richard, M. Coppel-Batsch... [et al.]. Paris: EDK, 2002: VII-VIII.

Lejoyeux Michel. «Le jeu pathologique: aspects littéraires et culturels ». L'Autre 7/2 (2006): 231-242.

Neyraut-Sutterman Thérèse. «Parricide et épilepsie. A propos d'un article de Freud sur Dostoïevski». Revue française de psychanalyse 34/4 (1970): 635-652.

Roudinesco Élisabeth. Histoire de la psychanalyse en France. Vol. 1. Paris: Le Seuil, 1982.

Sédat Jacques. «La réception de Freud en France durant la première moitié du XX $\mathrm{X}^{\mathrm{e}}$ siècle. Le freudisme à l'épreuve de l'esprit latin». Topique 2/115 (2011): 51-68.

Vion-Dury Juliette. «Jeu, création et liberté dans Le Joueur de Fédor M. Dostoïevski et Le Joueur D'Échec de Stefan Zweig». Droits 63/1 (2016): 113-126.

\section{LITERATURE}

Bogdanova Ol'ga. «Mif Dostoevskogo v Rossii i Germanii 1920-h godov: peripetii i paradoksy kul'turnogo transfera». Mundo Eslavo 16 (2017): 9-18.

Comte-Sponville André. «D’une passion l'autre». Dostoïevski Fédor. Le joueur: extraits des carnets d'un jeune homme, nouvelle traduction d'André Markowicz, lecture d'André Comte-Sponville. Arles: Actes Sud, 1991: 219-234.

Eiguer Alberto. «Dostoïevski, meurtrier ou joueur». Babel: psychanalyse et littérature: [actes du séminaire]. Dir. M. Corcos, P. Lévy-Soussan, E. Sabouret, M. de M’Uzan, F. Richard, M. Coppel-Batsch... [et al.]. Paris: EDK, 2002: 25-54.

Enciklopediya glubinnoj psihologii. Tom 1. Zigmund Frejd. ZHizn', rabota, nasledie. Moskva: MGM-Interna, 1998: 80-81.

Fernandez Dominique. «Introduction à la psychobiographie». Nouvelle Revue de psychanalyse. 1 (1970): 33-48.

Fernandez Dominique. «Préface». Dostoïevski. F. Le Joueur. Paris: Gallimard, 1973: 1-15.

Fokin Sergej. Figury Dostoevskogo vo francuzskoj literature XX veka. Sankt-Peterburg: RHGA, 2013.

Frejd Zigmund. «Budushchee odnoj illyuzii». Sumerki bogov. F. Nicshe, Z. Frejd, E. Fromm, A. Kamyu, ZH. P. Sartr. Moskva: Politizdat, 1989: 94-142.

Frejd Zigmund. Hudozhnik i fantazirovanie. Per. s nem. Pod red. R. F. Dodel'ceva, K. M. Dolgova. Moskva: Izdatel'stvo «Respublika», 1995.

Green André. «Préface». Babel: psychanalyse et littérature: [actes du séminaire]. Dir. M. Corcos, P. Lévy-Soussan, E. Sabouret, M. de M’Uzan, F. Richard, M. Coppel-Batsch... [et al.]. Paris: EDK, 2002: VII-VIII.

Lejoyeux Michel. «Le jeu pathologique: aspects littéraires et culturels ». L'Autre 7/2 (2006): 231-242. 
Nejfel'd Iolan. Dostoevskij. Psihoanaliticheskij ocherk. Pod red. Prof. Z. Frejda. Per. s nemeckogo YA. Druskina. Leningrad - Moskva: Izdatel'stvo «Petrograd», 1925.

Neyraut-Sutterman Thérèse. «Parricide et épilepsie. A propos d'un article de Freud sur Dostoïevski». Revue française de psychanalyse 34/4 (1970): 635-652.

Roudinesco Élisabeth. Histoire de la psychanalyse en France. Vol. 1. Paris: Le Seuil, 1982.

Sédat Jacques. "La réception de Freud en France durant la première moitié du XX $\mathrm{X}^{\mathrm{e}}$ siècle. Le freudisme à l'épreuve de l'esprit latin». Topique 2/115 (2011): 51-68.

Vion-Dury Juliette. «Jeu, création et liberté dans Le Joueur de Fédor M. Dostoïevski et Le Joueur D'Échec de Stefan Zweig». Droits 63/1 (2016): 113-126.

\title{
Олга Волчек
}

\author{
НОВАЦ У РОМАНУ Ф. М. ДОСТОЈЕВСКОГ КОЦКАР: \\ ПСИХОАНАЛИЗА, ПАТОЛОГИЈА И ЗДРАВЉЕ КЬИЖЕВНОСТИ
}

\section{Резиме}

Рад је посвећен анализи значења новца у роману Достојевског Коцкар у интердисциплинарним истраживањима француских научника, где се страст према хазардним играма попут рулета тумачи с аспекта психоанализе. Тему патолошке страсти према коцкању као моћног импулса за самокажњавање и самоуништавање први је дефинисао С. Фројд у чланку „Достојевски и оцеубиство“. Након што је постао увелико познат у Француској после 1973. године, Фројдов есеј је послужио као полазна тачка за компаративне, психоаналитичке, философске и радове о књижевности, у којима се коцкање у новац у роману не сагледава само као морална перверзија, болест зависности или илузија коју намеће јака жеља, већ и као могућност ослобођења и стварања.

Кључне речи: Достојевски, Фројд, новац, коцкање, патологија, психоанализа. 